\title{
$\stackrel{\alpha}{\sim}$ NTERNATIONAL REVIEW Of SOCIAL RESEARCH
}

Volume 4, Issue 2, June 2014, 5-24

International Review of Social Research

\section{Exploring the Communist Higher Education System. Contributions towards a Theoretical Framework}

\author{
Bogdan FLORIAN ${ }^{*}$ \\ National University of Political Science and Public Administration \\ Institute for Education Sciences
}

\begin{abstract}
The combination of education with industrial production' made the top 10 list of measures which have to be implemented in countries where the proletariat will raise as the ruling class, according to Marx's Communist Manifesto. It is ranked at the end of the list of necessary steps to achieve a new social order, however it endured and, in a slightly modified form it even exists today in higher education reform strategies.

To which extent has this ideological prescription been followed and inspired political measures? This paper aims at proposing a few steps in creating a theoretical framework for analysis of the role of higher education in the communist system. I will use an institutionalist approach to explore where higher education can be placed, in the larger context of the communist system. I will try and adapt to this topic the system paradigm proposed by János Kornai and explore higher education as a component of the larger communist system. Was it the universities' mission to produce an able workforce for the industrial development? Was there another scientific or ideological mission equally important? How well did the communist central planning system perform in matching industrial demand and educational production? These are some key questions to which this exploration aims at finding a framework for answering.
\end{abstract}

Keywords: communist system, higher education planning, command economy, János Kornai.

\section{Some raw data}

Unlike other research papers, we will start our exploration into the Romanian higher education system during communist times, by going through some statistical data. This will be followed shortly by a short review of some other papers approaching the subject of higher education during communist times and, at the end, will be summed up to provide a theoretical framework for analysis. It must be said, from the very beginning, that scientific literature on the way higher education functioned as a subsystem

•e-mail: bogdan_florian@yahoo.com. Bogdan Florian holds a PhD. in political science with a thesis regarding higher education policies. He currently works at the Department of Political Science at the National University for Political Science and Public Administration and also is a researcher associated with the Institute for Educational Sciences in Bucharest. His scientific interest and activities cover largely the area of public policies, with a focus on education and, more specifically higher education. His recent published papers and research reports cover themes such as higher education financing, quality assurance and access to education. 
in the larger framework of communist bureaucracies is scarce. What is even more interesting is that data itself, even in a raw format is rarely available and very general, at least for the Romanian case. This is all the more baffling since the outcome of the higher education process not only influenced the lives and actions of individuals but also the fate of entire families and was a source of possible explanations for inner country migration. The repartition mechanism largely used in Romania, but not only, which basically meant the allocation of a job to each higher education graduate was, in itself, a very interesting mechanism of central planning. At the same time, the individual strategies it generated, since not always people were willing to change their residence around the country and also the alternative mechanisms it produced need to be studied further, beyond the scope of this paper.

Statistical data on the Romanian higher education system are sketchy and rather general in content. We know how many universities there were and how many students but we do not know for sure, for example, the dropout rates, the completion rates and so on $^{1}$. Research on the matter of higher education during the communist times is also rather rare, with some notable exceptions, like Jan Sadlak's 'Higher Education in Romania, 1860 - 1990: Between Academic Mission, Economic Demands and Political Control' (1990). But that was published in 1990. We will look into the academic literature trying to make some sense of what was happening during the historical age of the communist regime in Romania. For now, refreshing some statistical data is a concern, since, in order to be able to analyze an object we must be able to define it, or describe it at least. First let's start with the money, since financial resources are always important. Statistical data ${ }^{2}$ shows that 'education' has been (together with 'culture' and 'scientific and scientific support') one of the activities of the national economy which suffered of a constant lack of investment from 1950 to $1985^{3}$. As the Figure below shows that the ratio of investments in those fields in the total national investments in economy had dropped from 1950 - 1985 by almost one percentage point. This is huge, when at its peak investment in any of those fields barley amounted to one point five per cent in the total national investments in economy.

While science and culture somehow showed signs of revival towards the end of the period, education was clearly (and by far) the last on the priorities list when it came to investments. Just to get an idea, according to the same data, 'Industry' (obviously the champion when it came to investments) boasted at its peak a fabulous 50 per cent of all investments made in the national economy (the year was 1980). Shortage of financial resources in education was, undoubtedly, a reality during the entire timeframe and figures showing the structure of expenses also emphasize the gross and constant underfinancing of this system. Figures show that as total expenses rose sharply in nominal values between 1950 and 1989, the ratio of financial expenditures on education (and culture) dropped (Figure 2).

Using GDP as a referential the situation looks even worse financially for the education system, but somehow better for scientific research (Figure 


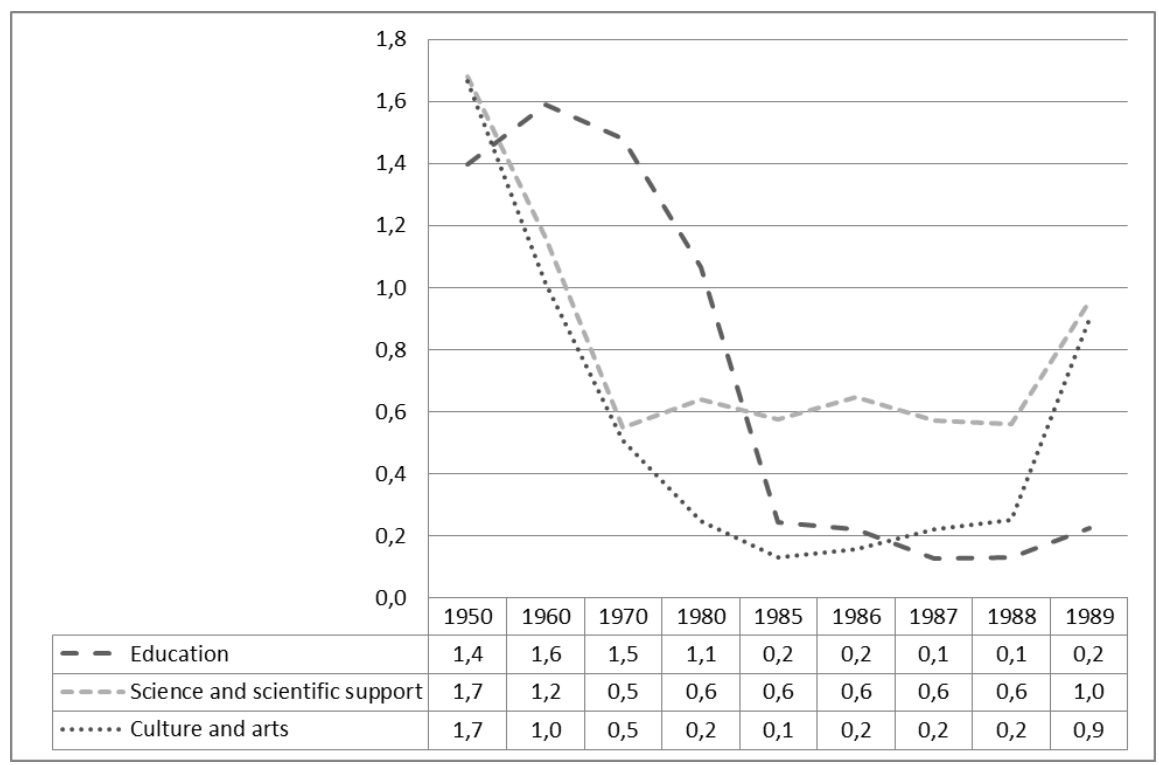

Figure 1. Evolution of investments in education, science and scientific support and arts and culture as a percentage of total investments in the national economy $(1950$ - 1989) Source: National Institute of Statistic Yearbook 1990.

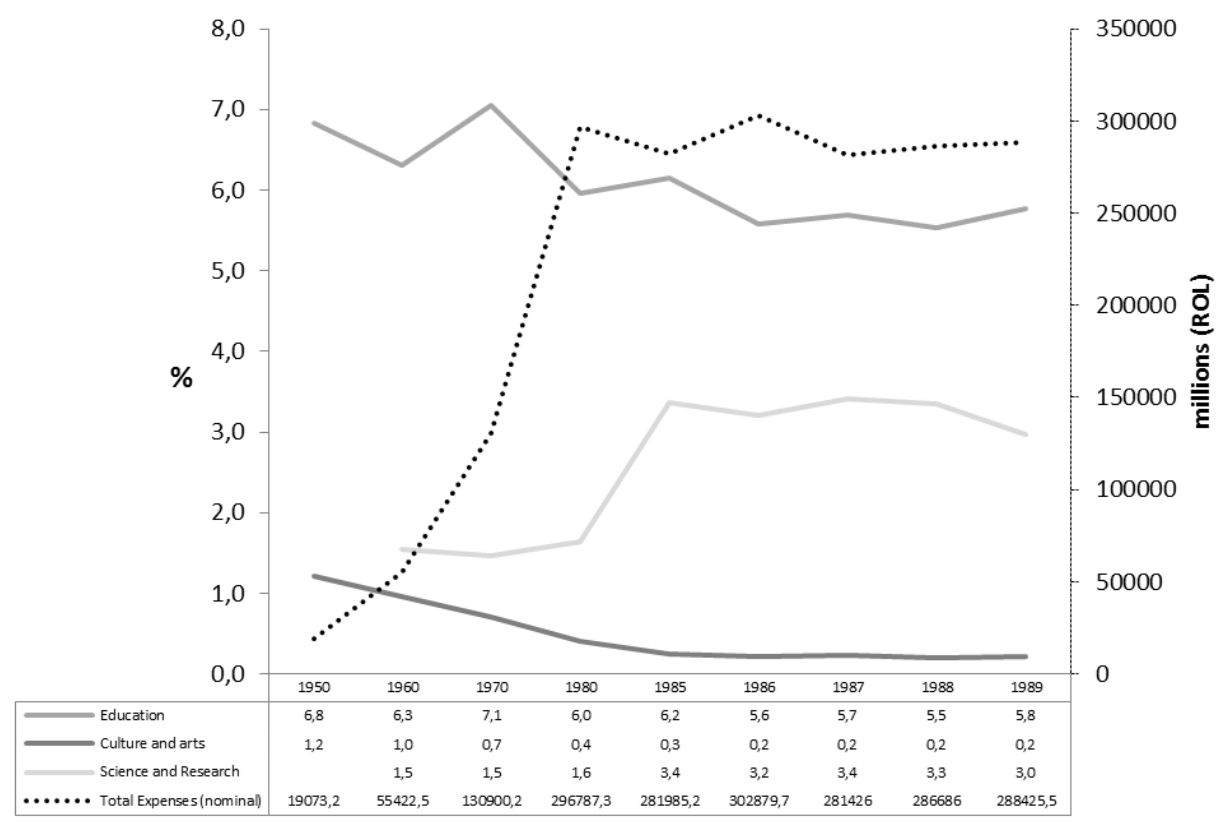

Figure 2. Total budgetary expenses and ratio for education, culture and science (1950 1989)

Source: National Institute of Statistic Yearbook 1990.

$3)$. It seems that while education was at the bottom of the priority list when it came to investments or expenses (excluding culture and arts), research and scientific activities gained some importance, apparently after 1980. A minor, but revealing, statistical detail must be underlined here. While 
expenses for education are listed in the 'General expenses for social and cultural activities', together with social protection and assistance (like pensions or child support), scientific research is listed in a different place under the heading 'Financing of the national economy'. In my view this small detail is important since it points to the fact that, to some extent, scientific activities had a higher importance, compared to education, for the regime. One belonged to social activities while the other contributed to the rise and development of the national economy. This may offer a brief explanation why financial resources allocated to research related scientific activities doubled (from one point five per cent to three per cent) in the structure of the total budgetary expenses of the Romanian state between 1960 and 1989.It is also worth mentioning that, looking only at the 1980s data (Figure 3), one can easily observe that as expenses for education lowered expenses on research rose and vice-versa. This points at an interesting trend: it seems, although we will never fully know, that, at least for the last 10 years of the regime, there was a constant allocation of resources to education and research, which was divided between the two. A zero sum game, if we can use this term here, in which neither research nor education actually won. Leaving aside all speculation, we can draw a partial conclusion from the data above. Education was clearly at the end of the list of priorities when it came to investment or expenses for the Romanian communist administration. Scientific research gained some importance from a budgetary perspective, during the 1980's, however that maybe only apparent since financial resources allocated towards scientific research seem to have varied in a relationship of inverse proportionality towards those allocated to education. While impossible to estimate what is the proportion corresponding to higher education from these general figures pertaining to education, it is safe to assume that it is a rather low one. The main reason being that higher education was underdeveloped in Romania, both in terms of size (number of universities or number of employees) and in terms of number of students. What is even more interesting is that statistical data presented below actually shows that higher education contracted spectacularly over the timeframe and especially during the 1980s. This was to be expected as a normal outcome of the constant underfinancing of the education sector as a whole, but it is dramatic in the context of an increasing demographic pressure which built up. This phenomenon points out that there might have been a policy of constant 'under-education' of the population, a conclusion which can also be supported by the arguments of other authors.

In short: the number of universities shrinked, the number of faculties dropped, the number of students rose (but only in nominal values), the number of graduates followed the same pattern (naturally), the number of university teachers rose (somehow paradoxically) and the structure of different academic specialization was deeply altered over the course of just thirty years. This is, briefly, what data shows us.

The number of universities decreased from 54 higher education institutions officially recorded in 1950, according to the National Institute 


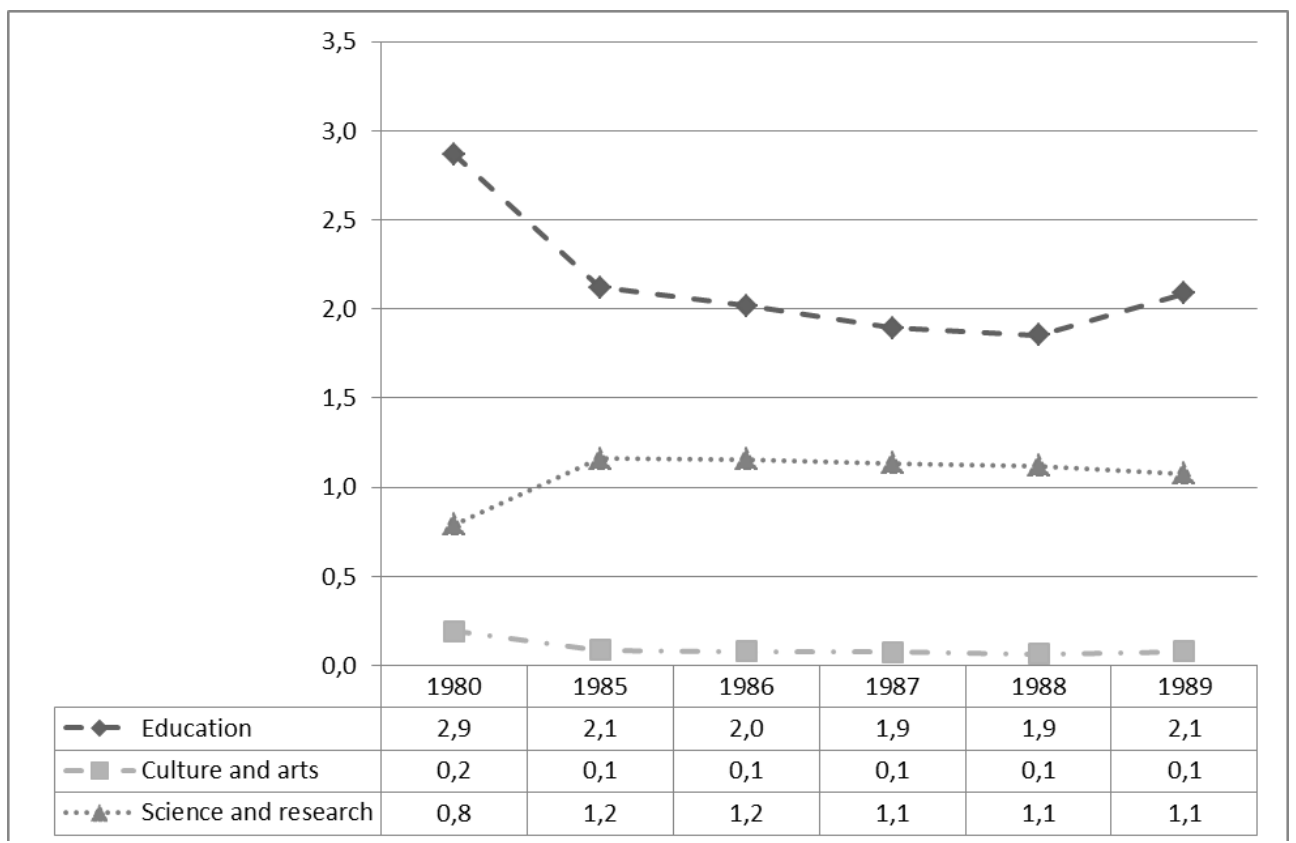

Figure 3. Expenses on education, culture and science as a percentage of GDP (1980 - 1989) Source: National Institute of Statistic Yearbook 1990.

for Statistics Data, to 44 institutions in 1989. The number of faculties (departments) also shrunk accordingly from 136 to 101 during the same period of time. The number of enrolments rose from 53,007 enrolled students in 1950 to 164,507 at the beginning of the $1989 / 1990$ academic year, with a peak of almost 200,000 enrolments in the mid 1970s. The numbers of graduates had a more dramatic variation starting from 9510 graduates in 1950, rising to 71,658 graduates in 1985 and then dropping sharply to 27,620 only four years later in 1989. The numbers of academic staff also oscillated from 8,518 persons in 1950 to a peak of 14,592 in 1980 and then to 11,810 in 1989.

However, those numbers do not necessarily tell a nice story about Romanian higher education during communist times. This has been previously described and reported both by Sadlak (1990) and Murgescu (2010).
While Sadlak mainly used statistical data available in 1990, Murgescu turned to several sources (of course including Sadlak's account) to arrive at the same conclusion 'education, which in the first decades after the war was an influential factor for economic and social progress, had been pushed by the regime in a crisis and this crisis also amplified the more general crisis of the communist system in Romania' (Murgescu, 2010:391). I feel the need however to go back to the original data, as it is and leave aside all interpretation. I think that what happened to the higher education system, in Romania during the communist regime, can be better explained by Kornai's theoretical framework and through the use of concepts such as shortage. We have seen before that the education system as a whole functioned, for over thirty years in a situation of acute underfinancing (both in investments and current expenses). Therefore one 


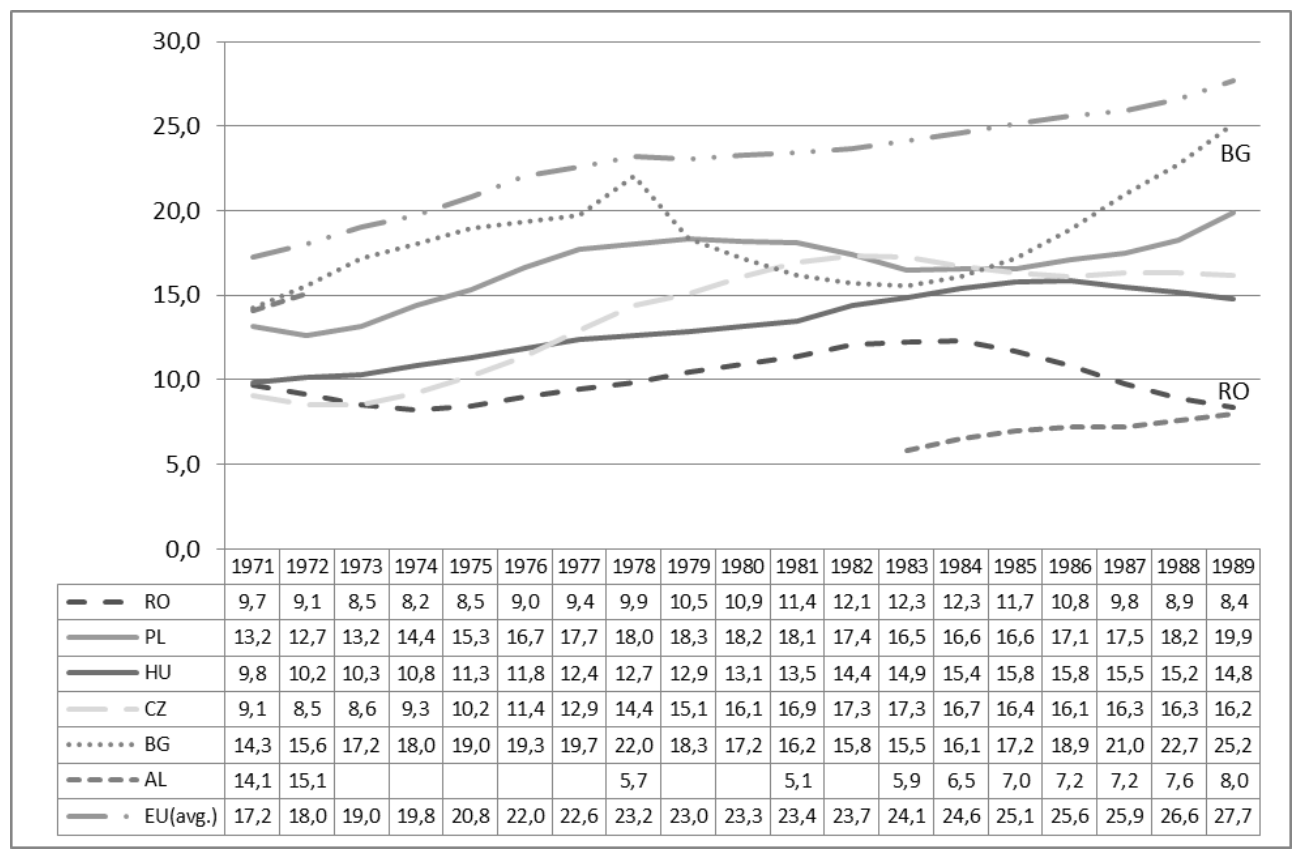

Figure 4. Gross enrollment rate selected countries (1971 - 1989)

Source: World Bank Education Database (2013).

cannot really expect the system to perform better during that timeframe. Also, figures (in absolute values) are often misleading and it is only when one tries to use some form of aggregation of those numbers that things become more striking.

First some indicators: the gross enrolment rate. The gross enrollment rate for tertiary education is a very important indicator, because it allows us to compare countries, years and also to better grasp the issue of access to higher education. By comparison (Figure 4) to other countries in the region the gross enrollment rate in tertiary education in Romania shows, by itself, the level of underdevelopment of the sector. A meager 10 per cent of the population was enrolled on average between 1971 and 1989 in a tertiary level education institution. In other words, over the course of twenty years only one in 10 persons with the theoretical age for access to tertiary education (19 to 23 years old) actually enrolled.

Figure four shows that not only Romania was, besides Albania, the lowest ranking country in Eastern Europe regarding enrollments in tertiary education, but it also was clearly the one with the worst track record for twenty years. If we look closely at the time series we cannot overlook the fact that in 1971, the figures were not that bad. In fact Romania, Czechoslovakia and Hungary had in 1971 around the same rate of enrollment. The following decades witnessed different courses of evolution for those countries. In numbers this means that in 1989 Romania had half the rate of enrollment of Czechoslovakia, starting from an advantage of almost one percent almost twenty years before. The comparison to Albania is also rather tricky, for if all conditions remained equal (from a 
political perspective); Albania had a serious chance to surpass Romania in enrolment rates in just two years' time.

State politics, legislation, different types of hurdles played their role, but there might be another part of explanation mostly overlooked so far. The distribution of universities and their geographical placement excluded most of the population from physical access to higher education. Coupled with the very low rate of investments in student services and infrastructure of universities (such as housing facilities for students) and an extremely low social mobility this led in a short time to disastrous effects. Without developing explanations at this point and only to offer a glimpse on the issue, I will jump ahead just a little bit. Romanian higher education policies were, as Murgescu describes them, 'inconsistent', at least in the 1940s and 1950s. That was a period dominated by purges, political persecutions and other extreme behaviors. In the 1960s and 1970s a coherent policy in the area of university education took shape, which combined some measure to stimulate access to the system [...among which building student homes] and rising the academic level (be recovering some of the academics previously excluded from academic life, reestablishing some discontinued study fields and specializations...) (Murgescu, 2010:387).

Student-homes building was the only thing in the list (which I did not reproduce entirely) made by Murgescu for which we actually have data. Figure five below shows the ratio of students living in a student home, which can be treated as a proxy for the number of spaces available for students coming from outside the city where the university was located. And there should have been a lot of those students, since universities were to be found only in Bucharest (12 universities),

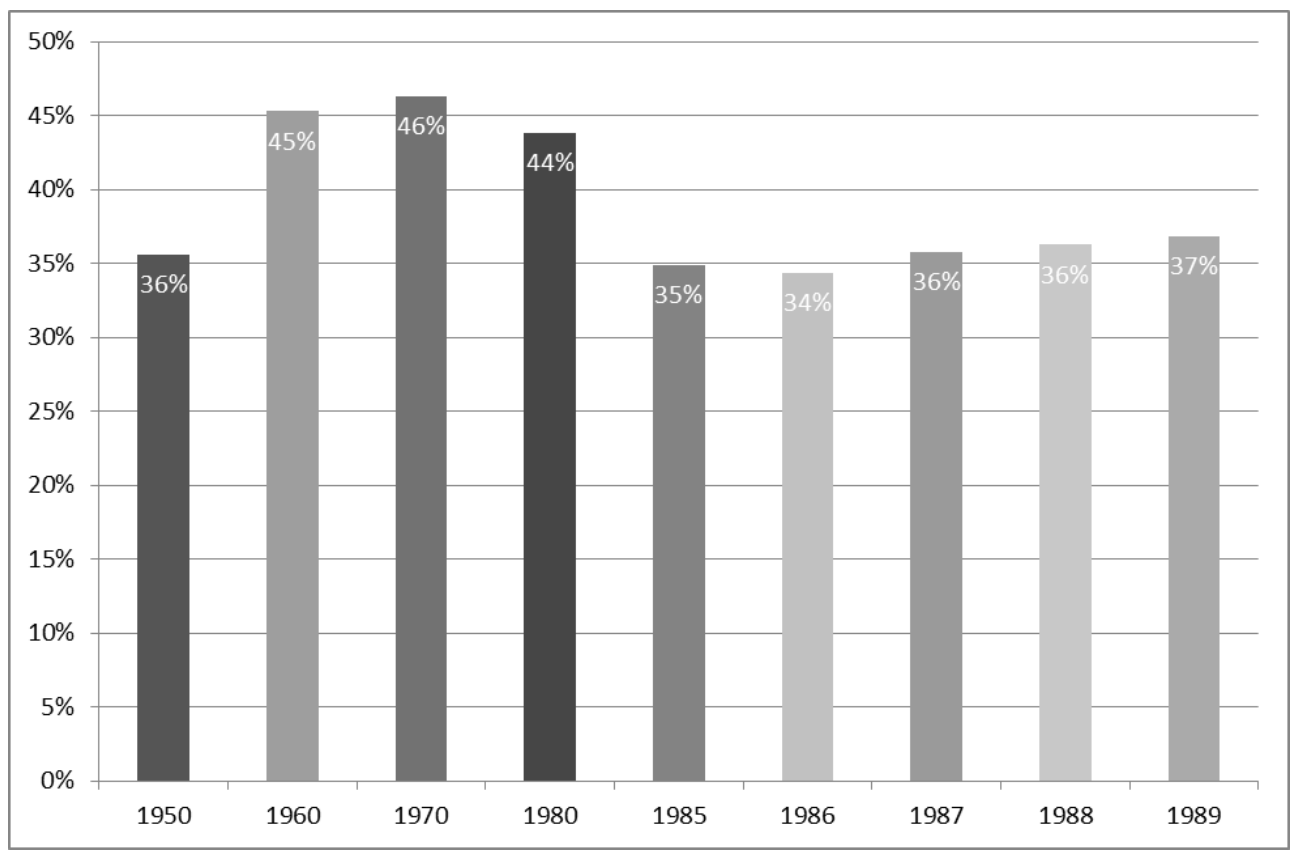

Figure 5. Ratio of students living in a student home (1950 - 1989)

Source: National Institute of Statistic Yearbook 1990. 
Cluj-Napoca (six universities), Iasi (five universities), Timisoara (four universities) and several other smaller cities with one university each. This great concentration of universities in a few cities meant, in fact, that student facilities (first of which was housing) had to be offered. This is why, in years like 1970 or 1980 , when the proportion of students living in student dormitories was close to 50 per cent, enrollment rates were also higher (nine point seven per cent in 1971 and 10,9 per cent in 1980 respectively). As housing facilities become more and more crowded enrolment rates started to drop. There is clearly not a year to year correspondence between the two indicators, but their evolution over the two decades points out the fact that, among other factors, the pure and simple shortage of housing for students was a factor in the declining gross enrolment rates.

Another peculiarity of the Romanian tertiary education system was the weight of different academic fields of study. As Sadlak (apud Murgescu, 2010) also notes, over 50 per cent of students were (in the 1980s) enrolled in engineering and technical study programs (Murgescu, 2010:389). What makes things even more interesting is that over a short period of time the number of students enrolled in different academic study programs varied hugely. But before exploring the evolution of student enrollments by different academic areas, another characteristic of the Romanian higher education system must be brought to light. A significant change occurred in the structure of the student population, somewhere in the 1980s. After what it is called the first 'opening' of the system (in the 1960s mainly), when the number of reduced frequency students rose (Figure 6), a return to a classical education system in the 1970 s, when the number of full time students was

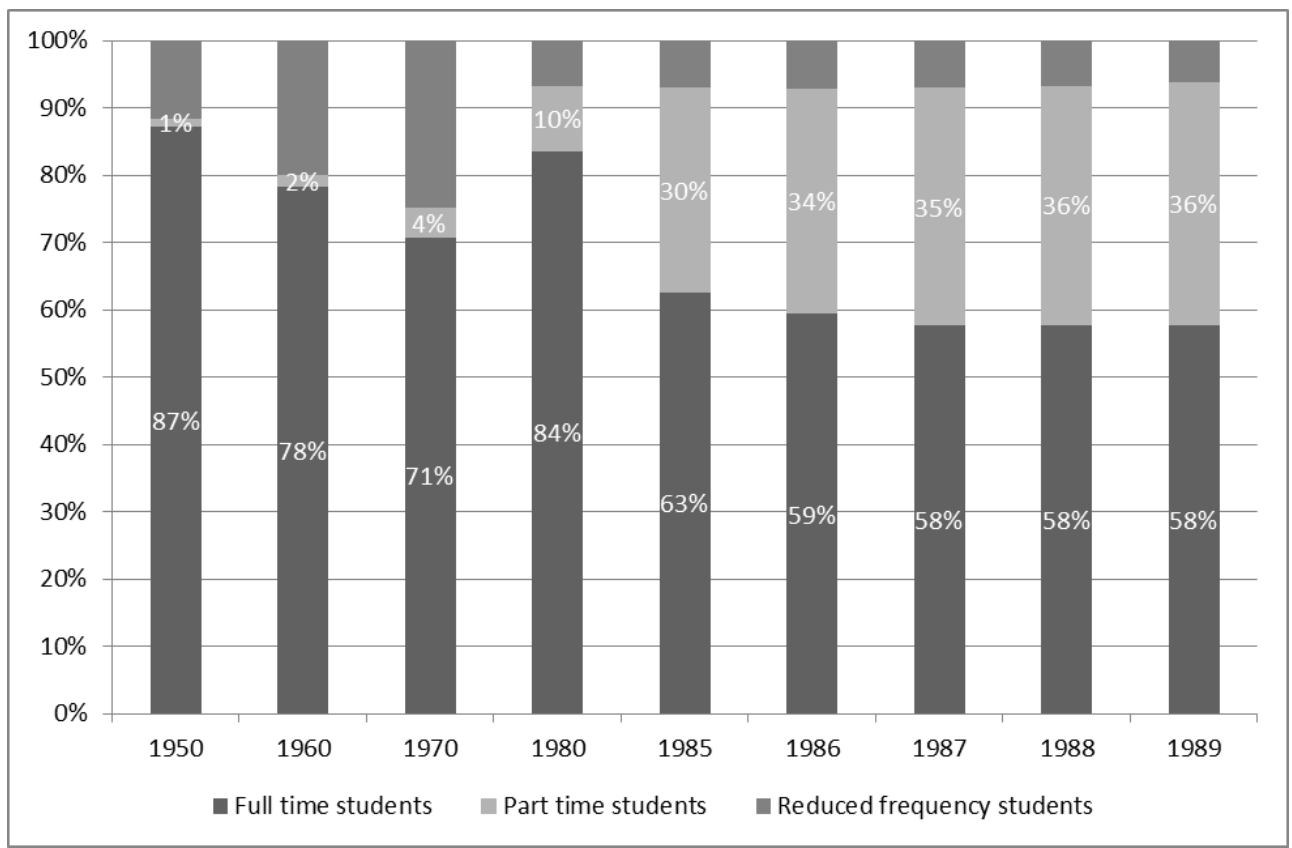

Figure 6. Student population composition by study intensity (1950 - 1989)

Source: National Institute of Statistic Yearbook 1990. 
restored to around 84 per cent of the total student population (in 1980), the entire decade that followed marked a significant change which meant increasing part time student numbers rising (in just five years between 1980 and 1985) to around 35 per cent of the student population.

It is not important why this shift occurred, it may have been due to the fact that in the 1960s and 1970s the political regime relaxed and tried to 'open' higher education, but also recover part of its 'quality' (Murgescu, 2010; Sora, 2011) by rehiring in universities several academics previously excluded. It also may have been due to the fact that in the same period of time a series of hurdles and bottlenecks preventing access to higher education had been removed or relaxed (diversification of study programs, introduction of short term higher education programs, facilitating access to higher education to employed adults - which meant almost every citizen with a valid certificate for completion of secondary education). An act from $1962^{4}$ for example stated that even persons who do not hold a valid completion certificate for secondary education but graduate from three years study programs in higher education institutions have the right to participate in a special examination for obtaining a secondary education completion certificate and their maturity certificate (equivalent of baccalaureate diploma granting access to higher education) (Art. 22). This basically meant that even dropouts having completed (at best) eleven years of formal education were allowed to get in three years' time a 'secondary level' education certificate and only two or three years later (depending on the study program and academic field they were studying) a higher education certificate. In other words, in five years' time an individual could, theoretically, get two study certificates (both for secondary and tertiary education) which, normally should have taken them nine (or more) years to complete.

This fast-tracking of higher education contributed clearly to the huge increase in the 1980s of the number of students getting enrolled in part time study programs (which meant they had to also be active on the labor market, at least formally). But this also meant that higher education was in fact nothing more than a sort of secondary education institution with some kind of extra content. Also the rather sudden and radical changes of the student body meant a constant need for adaptation and organization of educational contents, which is hard to believe could be done, leading, potentially to a decrease of the overall quality of study programs in higher education. Finally, the academic structure of departments and enrolled students completes the sketchy picture of Romanian higher education throughout the communist era. The radical changes in student enrollments by field and the structure of departments (faculties) within universities go hand in hand, naturally. Regarding the number of departments, official data shows that fluctuation was not frequent. There were two essential points in the timeframe analyzed: an increase from 1950 to 1970 in the number of departments (from 136 to 195). This was mainly due to an increase in the number of departments of pedagogy (from nine in 1950 to 66 in 1970). This was followed by a steep and quick decrease in the number of 
departments from 195 (1970) to 101 in 1986. This second period is marked by the virtual extinction of pedagogy (down from 66 departments to only 1 in ten years from 1970 to 1980) and the vast expansion of metallurgy and machine building departments from 11 to 21 (from 1970 to 1986).

It is also worth noting that some departments were actually liquidated in their entirety, this being the case of chemistry (no recorded departments from 1980 to 1989), pharmacology (no recorded departments from 1986 onwards) and even geology and geography which disappeared from official statistics also in 1986. This is not to say that those academic specializations disappeared, they were just no longer hosted in departments (faculties) but mixed in some other faculty of universities. The case of social sciences at the end of the 1970s and throughout the 1980s is, probably, the best example here. All social sciences were basically grouped together under the umbrella of the Philosophy Department and existed as 'specializations' of philosophy and lost institutional identity. The change in the number of students enrolled by academic specialization is, however, even more striking.

There is a clear pattern here, which has already been observed and described by Sadlak and Steliana Perț (apud Murgescu 2010). I return to these figures however, because they show first of all clearly that the main change in student enrollments started in the 1970s. It also shows, even more importantly in my opinion that increasing student numbers studying in the field of industrial studies (and not all engineering and other technical studies) is directly linked to the huge decreases of student enrolments in general university studies (including here humanities) and arts and agriculture. It also shows that most

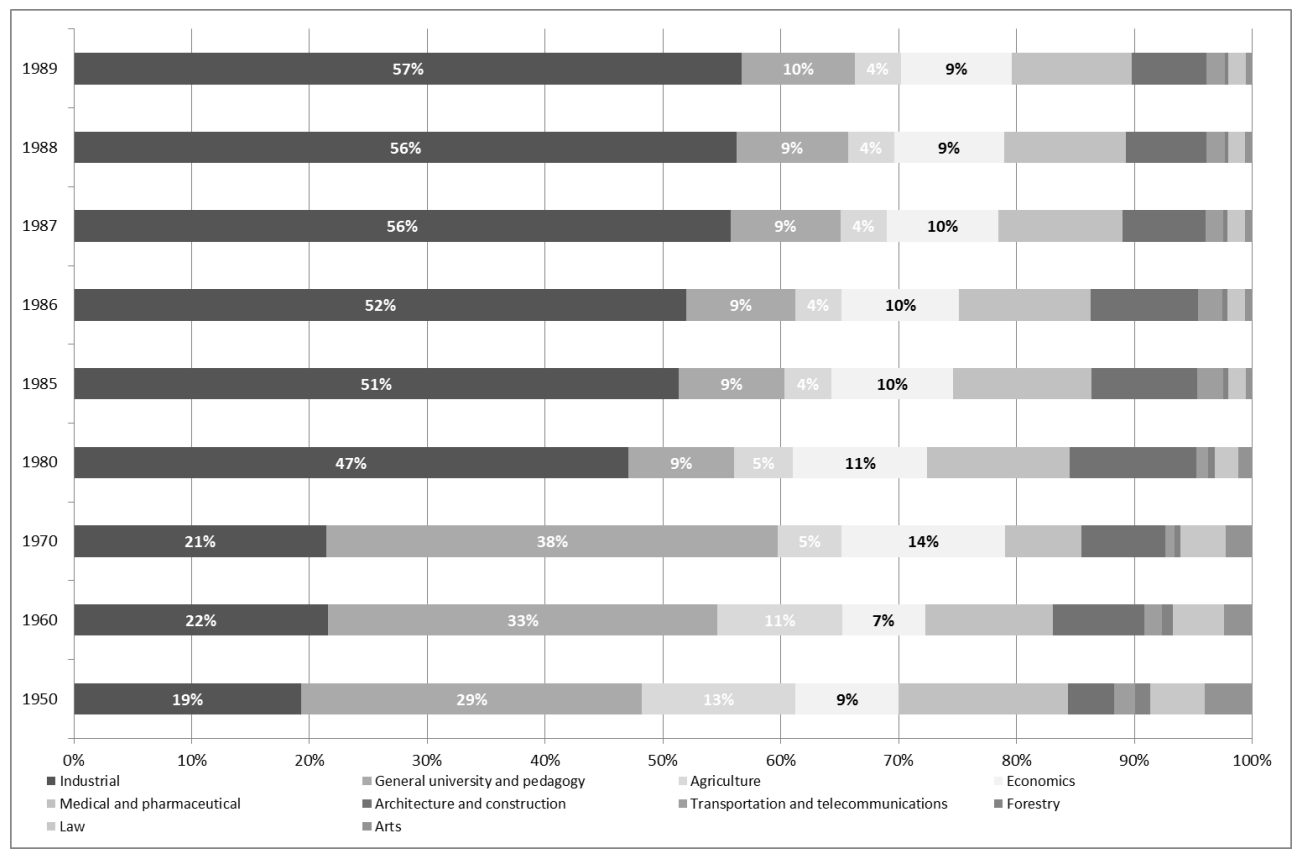

Figure 7. Changes in student enrollments by area of study and specialization (1950 - 1989) Source: National Institute of Statistic Yearbook 1990. 


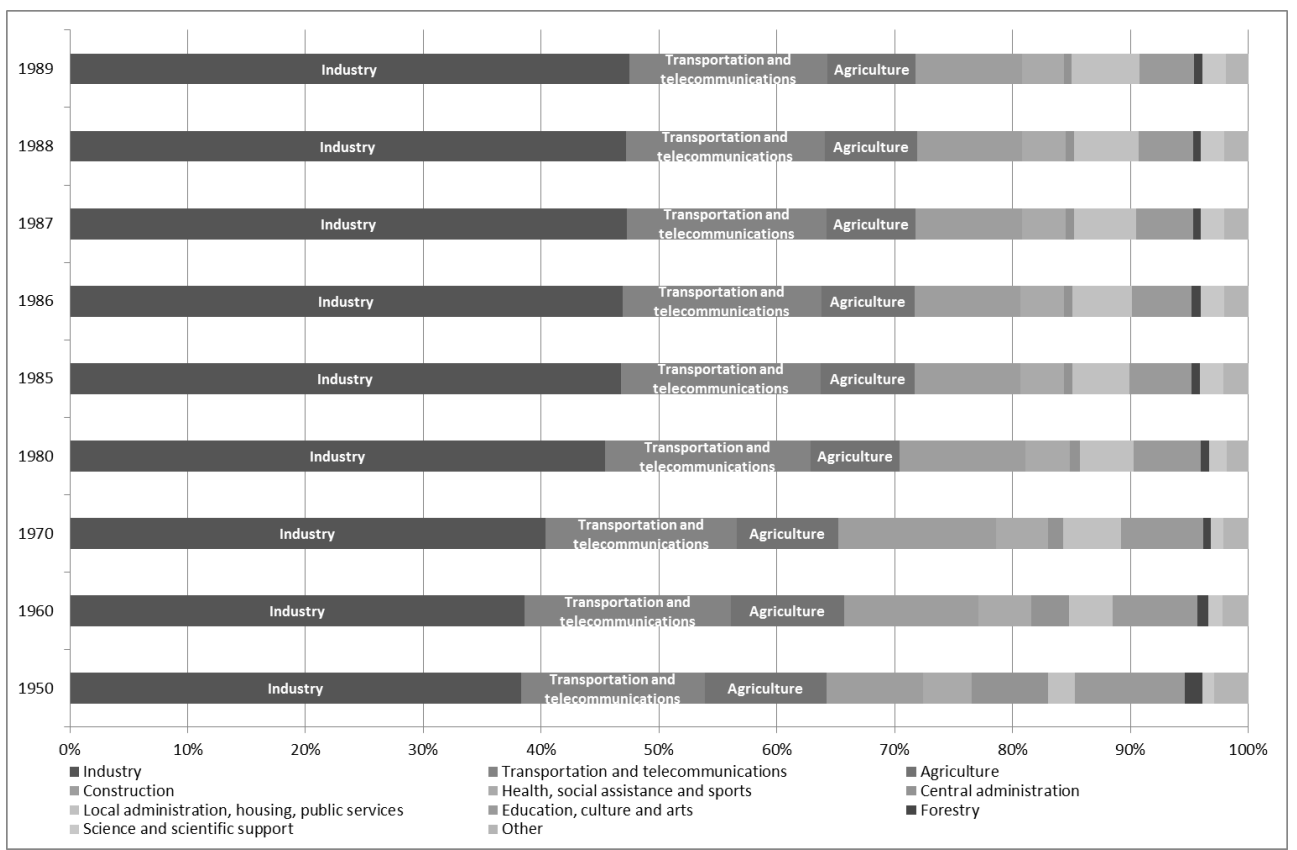

Figure 8. Evolution of the structure of the wage earners by economic activities (1950 1989)

Source: National Institute of Statistic Yearbook 1990.

academic specializations were not tampered with from this point of view and it also shows that medical students, even though they increased significantly in absolute numbers, in fact also decreased as a percent in the total student population. Student enrollments are important because, by themselves show that there was a clear hierarchy of academic specializations from the point of view of the political regime. It also shows that there was a clear plan or philosophy on the role of higher education: the production of a workforce which could be directly involved in industry. There was no place for other jobs or activities, not to mention research, scientific production, innovation and so on. People were trained to become industrial engineers, at least half of them, statistically speaking.

Finally, a quick glimpse at the structure of the labor market concludes our statistical description of how higher education looked like during the communist era. It is also important to remember that we started with a link between Marx's Communist Manifesto and communist regimes. We quoted the Manifesto, where, at the bottom of the top ten list of measures to be undertaken in a society where the proletariat will raise as the ruling class we found that education and industrial production have to be combined. In Romania this was taken literally in the form of compulsory practical productive activities for all persons involved in education (teachers, pupils, students etc.). There is another less literal form of interpreting this linkage: the matching of labor market needs and output of graduates from universities. In theory at least, the repartition system meant that for each graduate of a study program a workplace had to be assigned, preferably in an enterprise or 
other organization which operated in a field in which the graduated studied and was trained to be productive. So, how did the structure of the labor market looked? Looking at the evolution of the number of wage earners we can get a rough estimate of how well higher education and labor market were actually linked. Of course, not all economic activities require a higher education degree in order to be able to be hired but, generally speaking the structure of the labor market according to the number of wage earners hired shows the importance and magnitude of a specific economic activity within the system. Figures show that the structure of the occupied population according to the ratio of wage earners for each economic field was, not entirely surprising, quite different from the structure of the student body.

Industry clearly was predominant, but the increase in the number of wage earners is not as spectacular as the increase in the number of students in this academic field. At the same time the decrease in the number of education and culture and arts employees, whose ratio almost halved in the 1950 1989 timeframe (from nine point three per cent of the wage earning workforce to four point six per cent) was less dramatic than the reduction in the numbers of students in general university (including humanities and sciences) and pedagogy studies whose ratio decreased almost four times in, roughly, the same time period (from 38 per cent in 1970 to 10 per cent in 1989). Even though other reasons may also contribute to explaining these evolutions, such as demographics, it still is a spectacular fluctuation. It is also rather interesting to note that transportation and telecommunications employees remained rather constant throughout the same time frame and so did the public health and social assistance workers, while the ratio of central administration employees plummeted. This happened mainly due to the fact that the wage earning workforce constantly grew in numbers, while the central administration apparatus remained rather fixed (the ruling elite didn't multiply naturally as fast as the population).

From a statistical point of view, the education system in general and particularly higher education had a clear purpose. It was, like any other sub-system in the communist organization mechanism, a production tool. Its main purpose was to feed the economy with a somewhat qualified workforce. It also suffered from the same malfunctions as any other part of the mechanism and generated the same types of dysfunctions. Shortage and inflation (not in financial terms directly) can also be found within this sub-system. For example we can see clearly that a shortage in supply (the number of places in universities was severely limited) produced an inflation of students (and eventually graduates) in certain areas. Of course political decision weighted greatly, but so did other factors, such as alternative decision mechanisms, which have been described by Kornai (1991) and will be presented in the next section. Entering the second section of the paper we are trying to find out how and what kind of explanations can be found, other than the simple one of the political arbitrary decision making. In other words did this happen because communists implemented Marx and 
Engels's words literally? Did higher education in Romania especially have such shortcomings because it was basically designed to theoretically serve the direct needs of the labor market according to some official dogma?

\section{Search for an explanation}

Research on the topic of higher education in communist countries is not yet very developed, more so when one tries to find some form of analysis of the Romanian higher education system, how it operated, why certain events occurred and so on. This section is dedicated to finding some explanations and insights into how and why certain phenomena occurred. There are several approaches which offer explanation to some level on why and how the system was structured and operated in the way described above. It is important to note from the beginning however that those explanations seem to be based on a sort of shared understanding and personal interactions with the system, rather than objective scientific analysis. This is not a critique, but a fact, and is easily explained by the fact that access to any type of data was virtually impossible.

It is commonly agreed that the higher education system in Romania was a system designed for 'labor-force breeding units in line with ideological norms' (Dobbins and Knill, 2009, apud Mihăilescu and Vlăsceanu, 1994:318). This view is also shared by Sadlak who states that 'the design of this regime was to reduce institutions of higher education to mere centers for training a limited number of highly qualified workers' (Sadlak, 1994:13). Scientific research and education were two separated processes even from the point of view of the organizational structure: higher education institutions provided education while research institutes provided research and innovation. Thus, scientific research in universities was 'dramatically limited, which in turn led to distorting the mission of those institutions' (Mihăilescu, 2003). One other factor that had an importance was the structure of the Communist Party organization, which was unitary, comprising both university and research institutes. Lack of funding both for investment and current expenses has also been mentioned here and is also widely mentioned in Murgescu (2010), Mihăilescu (2003) and Pasti et al. (1996). Moreover it has been argued that one of the most devastating effects of the policies implemented during communist times led to the 'isolation of an entire generation ( $35-45$ years old) from research and education and its forced integration in [industrial ${ }^{5}$ ] production.' (Pasti et al., 1997:123). In short: Romanian higher education institutions were production units for elite skilled workers, grossly underfunded and also lacking any formal relationship to other scientific activities such as research. Of course, as Murgescu (2010) notes, the regime was not always so hard on universities themselves and that in the 1960s and partly 1970 s a sort of opening of the higher education system could be felt. This mainly affected access to higher education, since some restrictions for access had been abolished and also the reintegration of previously purged intellectuals and finally the reintroduction of some of the previously eliminated academic 
specializations (Murgescu, 2010). This view is also shared by Sadlak (apud Dobbins and Knill, 2009) as a consequence of Ceausescu's 'divorce' from Moscow, a slight liberalization of the academic sphere took place and academic cooperation with the West developed rapidly, enabling academics to participate in technology transfer' (Dobbins and Knill, 2009:413). Also, the law of education of 1978 was deemed as a fundamental change of the views and policies for education: 'education was supposed to provide for young people a strong theoretical background in strong sciences mathematics, physics, chemistry and biology - and also contribute to the internalization of the revolutionary conception of the world, history and the cult of nation. The 'multilateral initial formation' of young people was sought.' (Sora, 2011). Was this really the case?

I tend to believe the contrary: there is a great discrepancy between official rhetoric (to be found even in laws) and actual facts. I think that, as data shows and as some authors also have noted, it is precisely during this time of apparent freedom (the end of the 1960s and the 1970s), when the Ministry of Education was run by technocrats (Murgescu, 2010) that the plan of transforming higher education in a factory type of organization was finalized and strongly entrenched. First of all it must be noted, in all fairness, that the education law of 1978 was the one which institutionalized a practice that existed before but was never formalized: the 'integration of education and production 'including' practical activities in production' (Sora, 2011). This was to be a textbook example of a good idea gone bad in practice. Instead of mixing education with practical activities in higher education programs, 'practical activities in production' ended up meaning a compulsory hard labor activity for students and teachers alike, either in factories, agricultural related activities or even community services.

Second of all it must be noted that starting from 1975 all decisions regarding student numbers (the number of eligible places for each study program in each university) was no longer taken by the Council of Ministers but by presidential decree (Sora, 2011). Also, the statistical data show that it was precisely between 1970 and 1980 that a huge shift occurred in the student population and during those ten years the predominance of students enrolled in industry related study programs in fact occurred. Finally, a third argument which sustains the idea that the 1960's and 1970's were in fact a time of securing the grip of the regime over all social, cultural and economic life, when freedom was an illusion in the form (in the case of higher education) of granting access to a handful of academics to foreign books, reviews and rarely conferences, is related to planning.

Higher education, as any other system was subject to central planning of activities. From inputs to outputs and outcomes higher education was planned thoroughly and minutely. Or was it? In fact, so far we do not know exactly how thorough planning was, or what were the criteria and process which in practice lead to certain results. For example we do not know who, how and when decided that the number of places allocated to universities for 
industry related study programs should rise to 50 per cent of the total. Clearly, numbers and statistics were not really used, since if one looks at the wage earners structure we see that the shift in the labor market was rather slower towards industrial occupations. In other words, pure math only shows us that in fact, Romania started training industrial engineers only after it built an industry for them. And, to go the end of the argument, it is somewhat ironic that when Romanian universities started mass-producing of engineers and the first products started coming out of the factory, there was almost no industry left for them to work in ${ }^{6}$.

So I believe that the key to creating a theoretical framework which might explain why and how it all happened is planning and related theories to that. Before going into the theoretical framework, a few words about planning itself should be put forward.

\section{Planning, shortage and inflation - three key concepts for an analysis framework.}

Sadlak (1986) listed three main approaches to the concept of planning, which summed up the techniques used both in the western and eastern parts of Europe when it came to higher education steering: 'namely social demand, manpower planning and rate of return.'(Sadlak, 1986:398). Of the three, clearly manpower planning was the main driver of planning higher education in communist countries, Romania included, since, in theory, the number of students was directly linked to the forecasted number of necessary employees for different economic activities which required a higher form of training beyond compulsory education. Manpower planning for higher education meant basically the matching of manpower needs of the economy to the output of graduates (and naturally the input of admitted students) of higher education institutions. This was, according to Sadlak, a task easier said than done, since even though based on the 'socalled perspective plans which are usually of five years duration' a number of parallel processes intervene and 'bend' the initial planning (Sadlak, 1986:403). This is even more true of Romania, Sadlak argues, because even in the Romanian system 'with its rigid application of the manpower approach to higher education planning, the actual formulation of the plans is not merely a technocratic activity, but also involves several political factors, interest groups and other pressures, which may considerably affect their final form' (Sadlak, 1986:403). There are also three reasons, deriving from basic economics, which further prevent manpower planning to actually having a sustainable result: the impossibility of forecasting of job opportunities or redundancies (even in an autarchic and closed economic system such as Romania's in the 1980s); industrial employers are unable to evaluate their economic position in the long term and cannot communicate to the education system in time their needs and, thirdly, modern technology maybe labor intensive to research but it is rendering services and production less and less labor-intensive (Sadlak, 1986:403).

The consequences of using manpower planning widely and for a long period of time, for Romania, but also in other communist countries 
(including the Soviet Union), were equally devastating and surprisingly shared. Sadlak quotes in his 1986 paper a Polish author saying that, ever since 1968 Poland was overproducing engineers and that only 60 per cent of those engineers actually were employed in jobs requiring a university-level education. Another author quoted by Sadlak also pointed out that, since a large proportion of graduates could not be employed in their area of specialization, the estimated cost on the Soviet budget was of around one to three billion rubles wasted or misinvested (Sadlak, 1986:403). Finally, a common effect, which is also clear if we look at Romanian statistical data is directly related to enrolments. Sadlak observed in 1986 already that both in eastern and western Europe manpower planning 'led, during the 1960 s and early 1970 s, to a growth in enrolments, succeeded by much slower growth or a total leveling out from the mid-1970s onward.' (Sadlak, 1986:405). In Romania this effect is also clearly observable with the exception of 'leveling' turning in the 1980s into 'lowering' enrolments. There is enough ground now to advance our theoretical and explanatory framework a bit. It is clear, that, as any other part of the planned system, Romanian higher education, no matter how small and underfunded was subjected to a series of effects and consequences which were rather deterministic in nature. It does not mean ideology did not play a part, but it is not, in my view a sufficient explanation for the phenomena. I think that by using the 'integration of education and production' formula in a rigid manner and consequently reverting to the manpower planning as the only and rigid technique of steering higher education both contributed to producing the results we have observed. In Romania's case, there is another detail which is rather important and has been missed: Romanian communist decision maker(s) conceived higher education only as a production tool of workers and didn't assign to it another role, usually seen in other communist countries that of 'the development of the 'socialist' intelligentsia' (Sadlak, 1986:402). At least during the 1970s and 1980s this is easily defendable if we look at student enrollments and wage earners structure. Other arguments may be used to defend this: the way education laws defined higher education and its purpose, the gradual reduction of all branches of academic studies, except the polytechnics and so on.

We see that all higher education areas not leading to a directly and applied job, like general university, humanities, arts, fundamental sciences, law and so on were constantly decreasing in student numbers. At the same time, the central administration, education, cultural and other activities deemed as non-productive constantly had a smaller proportion on the labor market. In the context of inexistent investments in higher education, of ever lowering of the expenses on education, the manpower planning approach used led, in Romania, to an ever and constant increase of the ratio of students enrolled in industrial study programs. This was done at the expense of most of the other academic fields, since the number of places available in higher education was rather constant throughout the period, due to objective factors (shortage of resources). The outcome of this process was that of creating a shortage of supply in 
higher education in certain fields and, associated with it, an inflation of graduates in other fields, in other terms a waste of resources, a gross unbalance. The effects of this phenomenon are even more dramatic since, one must remember that we are discussing here people, their lives and the level of competencies and education, in short the development of human capital.

Let's now turn to the final elements of our argument: shortage and inflation and their form of manifestation in higher education operation as a sub-system. Shortage, inflation and investment hunger were all three widely discussed and described by János Kornai in his influential work The Socialist System. The Political Economy of Communism (1991). Kornai has as his main object of study economics and looks at various processes within the classical communist system of political rule. I think that his framework can easily be used to explain what happened not only economically within communist regimes, but also in terms of human capital formation, namely higher education functioning. It is important to note, firstly, that Kornai observes that effects of different policies and institutions have the tendency to react upon their own causes. In Kornai's own wording:

As the classical system consolidates, its elements develop coherence. The various behavioral forms, conventions and norms rub off on one another. [... The monolithic structure of power, petrified ideological doctrines, almost total domination of state ownership, direct bureaucratic control, forced growth, shortage and distrustful withdrawal from most of the world all belong together and strengthen each other. (Kornai, 1992:366)
This monolithic system develops its own mechanisms and institutions start going through a 'natural selection process', during which they root or they get discarded (Kornai, 1991). Interestingly enough for our topic, Kornai chose the example of close planning of personnel affairs. This is directly linked to higher education, since, as we noted, starting from the inputs (the number of places in universities available for students) to outputs and outcomes the state had total control on higher education institutions. This was part of the planning of personnel affairs, which included the reparation system which awarded a workplace for each and every graduate. This is what Kornai uses as an example for an institution which 'grew organically within the system' since there are no recorded 'blueprints' for socialism which even slightly touched on such an idea.

Kornai develops little on the role education, in general, played in the economic communist system. Education was an important sub-system since it was supposed to fulfill at least two important missions: production of a qualified (somewhat) workforce and ideological education at all levels. Graduates from different educational levels were, in fact, one of the two resources any director of an enterprise needed to be able to fulfill their assigned plan of production. In short, starting from Kornai's words 'The head of the firm has an interest in receiving as easy a production assignment as possible and as plentiful a supply of materials and labor as possible to carry it out.' (Kornai, 1991:122) That is very important, since, planning of higher education started, as we have already shown, with manpower planning. In 
order for the necessary manpower to be planned by officials, firms needed to be consulted.

In fact, in Romania, planning of the available workplaces to be filled through the centralized repartition system by graduates started with ministries communicating to the Ministry of Education of their own needs for human resources. Since head of firms always tended to exaggerate their needs in terms of labor and materials, to be sure to have more than needed for fulfillment of the plan, the central planning unit had, in theory, to keep increasing the numbers of available places in study programs which would generate (in time) the necessary workforce to fulfill the requests received. At the same time the chronic lack of investments and the chronic underfinancing of current expenses of the education sector put a pressure on planners, since there was a constant shortage of available resources (places). Despite the huge demographic potential and pressure, planners were not able to accommodate students in universities not because of ideological reasons, but because there were not enough space and money to maintain and increase the educational capacity of existing universities. Although several policies were sought (and justified ideologically by the need to grant access to education to the proletariat) to compensate for this issue (like enrolling workers in universities even without a secondary degree, or massively increasing the number of part time students) it was impossible for the planners to increase the actual number of students in universities. Thus lead, in a rather short period of time to the effect of a massive inflation of the ratio of students in the field of industry in the 1980s. The reason is now very easily identifiable: there was a huge pressure from the newly built industrial facilities and their heads to receive qualified personnel; they needed engineers to operate production processes. This pressure was greater for factories then for other types of enterprises, such as social services, health or education services, because of sheer numbers (factory needed more engineers to be able to function than a hospital needed doctors for example) and the importance 'workers' and industry held in official discourse. Therefore, in just ten years from 1970 to 1980 the proportion of students in industry related study programs more than doubled (Figure 7). This happened concomitantly with lowering budgetary expenses for education and increasing the student population by almost 40,000 people. The pressure was too big and the system basically collapsed, hence the ever smaller number of students being enrolled in higher education after 1980. But demand for industrial engineers grew and at the same time, the institution of the role of higher education as a production facility for qualified personnel developed organically. Hence, the constant increase in the ratio of students in industry, at the expense of other academic fields, since places had to be subtracted from some part. The obvious contender was general university and pedagogy (including humanities and sciences), since it used to be the number one in numbers of students until 1970. Also law suffered since it also had a large proportion of students and lawyers were not really needed or asked for by 
anybody in the 1980s. Finally the Arts' area of study was virtually erased from higher education slowly starting from 1980. All the places taken away from those areas were directly allocated to industrial studies.

\section{Conclusions}

We have shown in this paper that an institutional framework can easily be adapted and used to explain what happened with the higher education system, in the particular case of Romania, during the communist regime. Not only participation in direct productive activities was imposed at all school levels (from primary school to university) and to all individuals (from teachers to pupils, students and their parents), but the allocation of places for universities was directly influenced by this. Technical, especially industrial oriented engineering study programs developed quickly in size at least. This has been a direct consequence of an effect that turned on its causes and generated in the end an institution which started to exist independently.

Universities became mere bureaucratic organizations with a clear objective: production of workforce for the industry, mainly, and some other economic activities but just marginally. The scientific mission of universities had long been taken away from them, even from the beginning of the existence of the communist rule in Romania science and higher education being formally and institutionally separated. The ideological purpose had to be maintained however and this was best achieved, in the context of the shortage economy by the simple introduction of specific courses in all study programs irrespective of their individual aims. This produced a huge effect of isomorphism which lasted well beyond communist rule. The planning system failed, naturally, as it did in other areas. Using the manpower allocation system of planning, central planners were able to produce a major unbalance in the higher education landscape, by allocating huge numbers (proportionally) to industry related fields while subtracting them from other specializations. This had massive effects on human capital formation even in the 1990s and are still to be observed today, in modern Romanian higher education. In fact planners were never able to match needs of the job market with production of graduates, what they did instead was to react (maybe unconsciously) to the effects of forced industrialization. By creating huge cohorts of industrial engineers after industry itself was built lead to a major inflation of qualified workers with nowhere to work according to their specialization. This also had a devastating effect on transition in Romania in the 1990s and should be further explored, especially in the context of industry slowly degrading and failing after the collapse of the regime.

\section{Notes}

1 Although hard to prove scientifically, based on personal interviews with representatives from the National Institute for Statistics, I found out that the archive containing education data has been largely lost. It has either been degraded by time, moved to other institutions (such as the National Archives) or it has never been inventoried and therefore cannot be 
accessed (the reader should understand here that it cannot be found since there are no labels on the boxes containing such data).

${ }^{2}$ Data used in this section comes from the National Institute of Statistics. Statistical yearbooks were used as a primary data source. The reader must take this data with caution, based on the fact that there are many source of unreliability. I choose to use this anyway since there are no other indicators officially available which could describe the 'state of the art' during those times. My argument basically is that, being the sole source of data, it may be used even if unreliable to describe trends at least or provide hints for further scientific research.
${ }^{3}$ Unless otherwise indicated all data in this section is quoted from the Statistical Yearbook 1990, published by the National Institute of Statistics.

4 H.C.M. 1052/1962 regarding the improvement of part time and reduced frequency for general culture and higher education.

${ }^{5}$ I felt the need to add 'industrial' here, since production is of many types and scientific production is also a form of production.

${ }^{6}$ Since it takes theoretically five years to train an industrial engineer and by 1990 the communist regime existed no longer and industry stared to crumble.

\section{References}

Dobbins, M. and C. Knill (2009) 'Higher Education Policies in Central and EasternEurope: Convergence toward a Common Model?'. Governance: An International Journal of Policy, Administration, and Institutions, 22(3): 397 - 430 Kornai, J. (1991) The Socialist System. The Political Economy of Communism. Oxford: Claredon Press.

Mihăilescu, I. (2003) Universitățile în schimbare (Changing universities). București: Ars Docendi.

Mihăilescu, I. and L. Vlăsceanu (1994) 'Higher Education Structures in Romania'. Higher Education in Europe, 19(4): 79-93.

Murgescu, B. (2010) România și Europa. Acumularea decalajelor economice (1500 - 2010). Iași: Polirom.

Pasti, V., Miroiu M. and C. Codiță (1997) România starea de fapt. Vol. I: Societatea. București: Nemira.

Sadlak, J. (1986) 'Comparing Higher Education Planning Approaches in Western and Eastern Europe'. European Journal of Education, 21(4): 397-408

Sadlak, J. (1994) 'The Emergence of a Diversified System: the state/private predicament in transforming higher education in Romania'. European Journal of Education, 29(1): 13-23

Sora, A. F. (2011) Evoluţia calificărilor din învăţământul universitar românesc 1968-2011. http://docis.acpart.ro/uploads/noi/Raport_istoria_calificarilor.pdf (consulted November, 2013). 